\title{
Erratum
}

J Ginseng Res Vol. 36, No. 4, 341 (2012)

http://dx.doi.org/10.5142/jgr.2012.36.4.341

Erratum:

\section{Investigation of Different Factors Affecting the Electron Spin Resomance-based Characterization of Gamma-irradiated Fresh, White, and Red Ginseng}

Jae-Jun Ahn, Kashif Akram, Deokjo Jo, and Joong-Ho Kwon

J Ginseng Res Vol.36, No.3, 308-313 [http://dx.doi.org/10.5142/jgr.2012.36.3.308]

A part of published title was misprinted in the title and abstract. The corrected title and abstract are printed below.

Corrected title

\section{Investigation of Different Factors Affecting the Electron Spin Resonance- based Characterization of Gamma-irradiated Fresh, White, and Red Ginseng}

\section{Corrected abstract}

First line:

Fresh (raw roots), white (dried), and red (steamed-dried) ginseng samples were gamma-irradiated at 0 to $7 \mathrm{kGy}$.

\footnotetext{
(c) This is an Open Access article distributed under the terms of the Creative Commons Attribution Non-Commercial License (http://creativecommons.org/licenses/by-nc/3.0/) which permits unrestricted non-commercial use, distribution, and reproduction in any medium, provided the original work is properly cited.
} 